IRA-International Journal of Management \& Social Sciences

ISSN 2455-2267; Vol.07, Issue 02 (2017)

Pg. no. 156-171

Institute of Research Advances

http://research-advances.org/index.php/RAJMSS

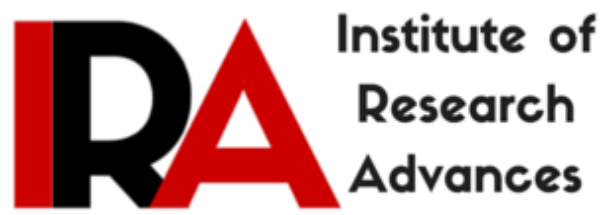

\title{
Predicting Sense of Coherence and Sense of Identity among Transgender People - Role of Perceived Social Stigma and Social Support
}

\author{
Gopica Anand ${ }^{1}$ and Swati Agarwal ${ }^{2}$ \\ ${ }^{1}$ Counselling Psychologist, Hyderabad, India. \\ ${ }^{2}$ Asst. Professor, St. Francis College for Women, Hyderabad, India.
}

Type of Review: Peer Reviewed.

DOI: http://dx.doi.org/10.21013/jmss.v7.n2.p5

\section{How to cite this paper:}

Anand, G., \& Agarwal, S. (2017). Predicting Sense of Coherence and Sense of Identity among Transgender People - Role of Perceived Social Stigma and Social Support. IRA-International Journal of Management \& Social Sciences (ISSN 2455-2267), 7(2), 156-171. doi:http://dx.doi.org/10.21013/jmss.v7.n2.p5

(C) Institute of Research Advances

\section{(cc) BY-No}

This work is licensed under a Creative Commons Attribution-Non Commercial 4.0 International License subject to proper citation to the publication source of the work.

Disclaimer: The scholarly papers as reviewed and published by the Institute of Research Advances (IRA) are the views and opinions of their respective authors and are not the views or opinions of the IRA. The IRA disclaims of any harm or loss caused due to the published content to any party. 


\section{ABSTRACT}

Sense of coherence is a global orientation expressing a person's pervasive and enduring feeling of confidence. The term "identity" refers to the capacity for self-reflection and the awareness of self. Stigma refers to a mark or sign of some sort that is seen as disqualifying individuals from the full social acceptance of the society. Perceived social support refers to an individual's belief that social support is available, is generally considered positive or negative and provides what is considered needed by that individual. The present study is a quantitative study which adopts a correlational design in which perceived social support \& transgender identity stigma are the predictor variables, and sense of coherence and sense of identity among transgender people, are the criterion variables. Purposive and snowball sampling techniques were used to include 120 transgender people aged between $18-50$ years from in and around the twin cities of Hyderabad and Secunderabad. Analysis of results through stepwise multiple regression analyses showed that social support is a predictor of sense of coherence and its dimensions - manageability and comprehensibility; and sense of identity. Perceived stigma was a significant predictor of comprehensibility while enacted stigma, predicted sense of coherence and comprehensibility. The application value of the study findings are high when it comes to formulating policies to improve the status of transgender community, taking into consideration their plight and the dearth of psychological research with this marginalised group.

Keywords: Sense of Coherence, Perceived Social Support, Perceived Social Stigma, Sense of Identity, Transgender

\section{INTRODUCTION}

Transgender is an umbrella term used to describe people whose gender identity (sense of themselves as male or female) or gender expression differs from that usually associated with their birth sex. Many transgender people live part-time or full-time as members of the other gender. Broadly speaking, anyone whose identity, appearance, or behaviour falls outside of conventional gender norms can be described as transgender. However, not everyone whose appearance or behaviour is gender-atypical will identify as a transgender person. Other categories of transgender people include androgynous, bigendered, and gender queer people. Exact definitions of these terms vary from person to person, but often include a sense of blending or alternating genders. Some people who use these terms to describe themselves see traditional concepts of gender as restrictive.

Transgender people experience their transgender feelings in a variety of ways. Some can trace their transgender identities or gender-atypical attitudes and behaviors back to their earliest memories. Others become aware of their transgender identities or begin to experience gender-atypical attitudes and behaviors much later in life. Some transgender people accept or embrace their transgender feelings, while others struggle with feelings of shame or confusion. Some transgender people, transsexuals in particular, experience intense dissatisfaction with their birth sex or with the gender role associated with that sex. These individuals often seek sex reassignment or to transform into another sex/gender.

Transitioning from one gender to another is a complex process. People who transition often start by expressing their preferred gender in situations where they feel safe. They typically work up to living full-time as members of their preferred gender, by making many changes a little at a time. Gender transition typically involves adopting the appearance of the desired sex through changes in clothing and grooming, adoption of a name typical of the desired sex, change of sex designation on identity documents, treatment with cross-sex hormones, surgical alteration of secondary sex characteristics to approximate those of the desired sex, and in biological males, removal of facial hair with electrolysis or laser treatments. Finding a qualified mental health professional to provide guidance and referrals to other helping professionals is often an important first step in gender transition. Connecting with other transgender people through peer support groups and transgender community organizations is also very helpful. 
Transgender people experience the same kinds of mental health problems that non-transgender people do. However, the stigma, discrimination, and internal conflict that many transgender people experience may place them at increased risk for certain mental health problems. Discrimination, lack of social support, and inadequate access to care can exacerbate mental health problems in transgender people, while support from peers, family, and helping professionals may act as protective factors.

Transgender people in most cities and countries can be denied housing or employment, lose custody of their children, or have difficulty achieving legal recognition of their marriages, solely because they are transgender. Many transgender people are also the targets of hate crimes. The widespread nature of discrimination based on gender identity and gender expression can cause transgender people to feel unsafe or ashamed, even when they are not directly victimized.

In general, Indians tolerate, accept, and respect a wide range of differences in cultures, religions, languages, and customs. Despite Indian society's general climate of acceptance and tolerance, there appears to be limited public knowledge and understanding of same sex sexual orientation and people whose gender identity and expression are incongruent with their biological sex. Human rights violations against sexual minorities including the transgender communities in India have been widely documented. Most families do not accept if their male child starts behaving in ways that are considered feminine or inappropriate to the expected gender role. Consequently, family members may threaten, scold or even assault their son/sibling from behaving or dressing-up like a girl or woman. Some parents may outright disown and evict their own child for crossing the prescribed gender norms of the society and for not fulfilling the roles expected from a male child. Parents may provide several reasons for doing so: bringing disgrace and shame to the family; diminished chances of their child getting married to a woman in the future and thus end of their generation (if they have only one male child); and perceived inability on the part of their child to take care of the family. Thus, later transgender women may find it difficult even to claim their share of the property or inherit what would be lawfully theirs. Sometimes, the child or teenager may decide to run away from the family not able to tolerate the discrimination or not wanting to bring shame to one's family. Some of them may eventually find their way to Hijra communities. This means many Hijras are not educated or uneducated and consequently find it difficult to get jobs. An official count of the third gender in the country is 4.9 lakh. While transgender activists estimate the numbers to be six to seven times higher, they are thrilled that such a large number of people identified themselves as belonging to the third gender. In Andhra Pradesh before bifurcation the no. of third gender persons is forty four thousand (TOI 2014).

Sense of coherence is a broad-band resource that is positively associated with coping with stress. Antonovsky (1986) defines sense of coherence as a global orientation expressing a person's pervasive and enduring feeling of confidence: (a) that the stimuli deriving from one's internal and external environments in the course of living are structured, predictable and explicable (comprehensibility); (b) that the resources are available to one to meet the demands posed by these stimuli (manageability), and (c) that these demands are challenges worthy of investment and engagement (meaningfulness) (1)

An individual's sense of coherence may either alleviate or aggravate reactions to a stressor and moderate the impact of occupational stressors on the individual's affective outcomes. This means that the impact of stressful experiences would vary for individuals with a strong and a weak sense of coherence (2) due to differences in their perception of the comprehensibility, manageability and meaningfulness of stimuli from the environment (3).

Among a sample of 1,135 Australian gay-identified men Lyons, Pitts and Grierson (4) found participants had moderate or high psychological distress. However, baseline distress was significantly lower among those with stronger baseline SOC. In addition, baseline SOC significantly predicted distress 12 months later. This predictive effect of SOC was independent of baseline distress levels and occurred despite a strong correlation between baseline and follow-up distress. 
A psychological identity relates to self-image (one's mental model of oneself), self-esteem, and individuality. Consequently, Weinreich (5) gives the definition "A person's identity is defined as the totality of one's self-construal, in which how one construes oneself in the present expresses the continuity between how one construes oneself as one was in the past and how one construes oneself as one aspires to be in the future". Gender identity forms an important part of identity in psychology, as it dictates to a significant degree how one views oneself both as a person and in relation to other people, ideas and nature.

Researchers (6) argue that, for LGBT individuals, gender and sexual self-identification are often intersectional, i.e., that self-understanding of non-heteronormative gender identity often involves selfunderstanding of non-heteronormative sexual identity and vice versa. This is partly due to LGBT individuals' experiences of societal oppression from any deviation from gender heteronormativity, whether of gender roles or sexual orientation. This intersectionality explains the differences found here in the trajectories of transgender individuals' transgender identity development, but also show how this intersectionality can act as a basis for non-gender heteronormative identity integration. This has important implications for working with LGBT individuals in counselling.

Testa, Jimenez and Rankin (7) found awareness and engagement with other transgender people influences risk and resilience during early gender identity development in 3,087 adult transgender participants. Prior awareness and prior engagement with other transgender people were independently related to less fearfulness, less suicidality, and more comfort.

Perceived social support refers to the various types of support (i.e., assistance/ help) that people receive from others and is generally classified into two (sometimes three) major categories: emotional, instrumental (and sometimes informational) support. Emotional support refers to the things that people do that make us feel loved and cared for, that bolster our sense of self-worth (e.g., talking over a problem, providing encouragement/ positive feedback); such support frequently takes the form of non-tangible types of assistance. By contrast, instrumental support refers to the various types of tangible help that others may provide (e.g., help with childcare/ housekeeping, provision of transportation or money). Informational support represents a third type of perceived social support (one that is sometimes included within the instrumental support category) and refers to the help that others may offer through the provision of information.

Amodeo, Vitelli,Scandurra, Picariello, and Valerio(8) found that participants with secure attachment styles reported higher levels of positive transgender identity than those with insecure attachment styles. Secure attachment styles significantly affect positive transgender identity, while insecure attachment styles influence internalized transphobia. 25 male-to-female (MtF) and 23 female-to-male (FtM) transgender people participated in the survey.

Quinn, Rounds and Munoz-Plaza (9) in their exploratory study on twelve 18-21 years old LGBT participants found that they perceived heterosexual and LGBT-identified friends and non-family adults as providing emotional and instrumental support. However, participants perceived limitations to the emotional support they received from heterosexual peers to whom they disclosed their orientation. In addition to providing emotional support, peers and adults who also identified as LGBT provided valuable informational and appraisal, support. Finally, most participants did not disclose to their parents during high school and perceived their parents and family members as offering limited emotional, appraisal and informational support. Confronted with their own sense of alienation and confusion, as well as the overwhelmingly negative messages about homosexuality in their home and school environments, respondents described their sexual identity formation as a process characterized by varying degrees of denial and acceptance.

Budge, Adelson and Howard (10) in a study with a total of 351 transgender individuals $(\mathrm{n}=226$ transgender women and $n=125$ transgender men) participants where the participants completed measures on transgender identity, family history of mental health concerns, perceptions of loss, coping, depression, and anxiety found that the rates of depressive symptoms (51.4\% for transgender women; $48.3 \%$ for transgender men) and anxiety (40.4\% for transgender women; $47.5 \%$ for transgender men) within the current study far surpass the rates of those for the general population. Social support was directly related to distress variables, as well as indirectly related through avoidant 
coping. Results suggest the need for practitioners to focus on interventions increasing social support, in order to improve mental health for transgender individuals.

Sheets Jr. and Mohr (11) investigated in a sample of 210 bisexual young adult college students. Results indicated that general social support was most predictive of depression and life satisfaction, whereas sexuality-specific support was most predictive of internalized binegativity. Both family support and friend support contributed to the prediction of depression and life satisfaction and internalized binegativity.

Wright and Perry (12) suggested that sexual identity-related distress may influence the physical health status of $\mathrm{g} / \mathrm{l} / \mathrm{b}$ people. Results indicate that sexual identity distress is strongly associated with psychological distress, less frequent use of alcohol, and using fewer types of illegal drugs.

Van Brakel and colleagues (13) provide a definition of perceived or felt stigma research as that in which "People with a (potentially) stigmatized health condition are interviewed about stigma and discrimination they fear or perceive to be present in the community or society. In the original definition, felt stigma 'refers principally to the fear of enacted stigma, but also encompasses a feeling of shame associated with [the illness]".

Individuals actively cope with stigma in ways that vary across stigmatized groups, across individuals within stigmatized groups, and within individuals across time and situations. The stigmatized are ostracized, devalued, rejected, scorned and shunned. They experience discrimination, insults, and attacks and are even sometimes murdered. Whether it is obvious to those around them or not, those who perceive themselves to be members of a stigmatized group often experience psychological distress. Although the experience of being stigmatized may take a toll on self-esteem, academic achievement, and other outcomes, many people with stigmatized attributes have high self-esteem, perform at high levels, are happy and appear to be quite resilient to their negative experiences.

Schofield (14) investigated possible protective factors using a secondary analysis of data from 108 self-identified transgender individuals who completed an extensive survey online. Findings show that being low in internalized transphobia, having fewer fears of gender-related rejection, and taking steps to transition are associated with more positive mental health outcomes for transgender people. This suggests that that those who have more confidence in their transgender identity are likely to have higher quality of life and self-esteem. Findings also suggest that social support from three major areas (immediate family, extended family, and friends) is associated with more positive mental health outcomes, including higher quality of life, higher self esteem, lower loneliness, and lower internalized transphobia.

Lewis, Derlega, Griffin and Krowinski (15) that perceived stigma is positively associated with symptoms of depression among gay men and lesbians. Experiences of prejudice and discrimination may reinforce expectations for rejection that the young person may develop as a result of heterosexism. The young person may feel the need to conceal their identity to avoid negative sanctions, and to remain constantly alert. This may result in considerable distress. LGBTQ youth do experience distress resulting from stigmatisation and this must be addressed in order to enhance wellbeing and to avoid the development of future difficulties. Poteat, German, and Kerrigan (16) stated that a growing body of literature supports stigma and discrimination as fundamental causes of health disparities. Increasing societal acceptance of the transgender community and decreasing gender-based prejudice may help prevent suicide in this highly stigmatized population (17).

Srivastava and Singh (18) examined the factors related to the negative attitude of society towards sexual minorities living in India. This study also explored further the impact of such stigmatization and carrying homosexual identity on the lives of lesbian and gay individuals. Results showed that homosexuality is a strong stigma in India and also demonstrated the adverse effect of the stigma on the lives and wellbeing of the sexual minorities.

Transgender people, as described earlier undergo/experience stigma as a result of their not being a part of the heteronormative people. Stigma may also expose them to numerous situations of discrimination and ostracization even from their family and friends. They also face a number of 
challenges which may make them feel isolated. Social Support is an established source of buffer from the difficulties they encounter in their lives as mentioned earlier identity particularly for transgender people is a long process continuing throughout their lives. Hence, stigma, discrimination and support available may play a role in the sense of identity of transgender people. Sense of coherence, a salutogenic concept, is an indicator of mental health and well being. Again, stigma on one hand and support on the other hand may play a significant and protective role on the sense of coherence in transgender people. To the best of researchers' knowledge, as research on these variables is limited, the present study intends to explore this further in the population of Hyderabad and Secunderabad.

Recent studies have shown the effect of perceived social stigma and perceived social support on the mental health and functioning of the transgender people. However the sense of coherence among transgender people isn't a widely explored area. Also, if transgender identities and the sense of coherence of the transgender people have to be studied, the influence of perceived social support and social stigma would play a vital role for accurate judgements. Hence, the purpose of conducting this research is to explore if there is a relationship between the mentioned variables and how one might predict the other.

\section{Research Objectives}

1. To explore the levels of transgender identity stigma and its dimensions- perceived stigma, enacted stigma and consequences of disclosure of transgender identity; perceived social support and its dimensions- appraisal support, belonging support and tangible support; transgender identity and sense of coherence and its dimensions- comprehensibility, manageability and meaning among transgender people.

2. To analyse whether perceived social support and its dimensions- appraisal support, belonging support and tangible support and transgender identity stigma and its dimensions- perceived stigma, enacted stigma and consequences of disclosure are predictors of sense of coherence and its dimensions- comprehensibility, manageability and meaning and transgender identity negativity in transgender people.

\section{METHOD}

\section{Research design}

The present study is an exploratory, quantitative study which adopts a correlational design to analyse the relationship between Perceived social support, Perceived social stigma, Sense of Coherence and Transgender Identity negativity among transgender people.

\section{Sample}

For the present study 120 transgender people aged between 18 - 50 years were taken into consideration for collecting data, from in and around the twin cities of Hyderabad and Secunderabad. The sampling techniques used were Snowball and Purposive Sampling.

\section{Instruments}

Information Schedule was used to collect background data and demographic details such as Age, State/Country of birth/residence, Religion, Relationship Status, Employment Status, Education completed, Living Arrangements, Physical and Mental Health Status. The Gender Identity Questionnaire (GIQ) was used in order to screen and include transgender participants in the sample. Apart from these, the following research tools were also used in this research. They were:

\section{Sense of Coherence (SOC) - Orientation to Life Questionnaire}

The Sense of Coherence Questionnaire measures the Sense of Coherence construct which reflects a person's capacity to respond to stressful situations. There are 3 dimensions of this scale, namely Comprehensibility, Manageability and Meaningfulness. Antonovsky's SOC scale(19) - life orientation questionnaire, has 29 items scored on a 7 point likert scale. Consensual validity which refers to the 
agreement of experts that a measure is valid, of the SOC scale seems to be moderate. Test-retest reliability of the scale range from 0.92 (one week), 0.65 (three weeks), 0.93 (one month), 0.77 (six months) using SOC-29. The internal consistency measured by Cronbach's ' $\alpha$ ' ranges from 0.70 to 0.95 using SOC-29. Some of the items were reverse scored. The overall range of the scores for all the items is $29-203$ \{Manageability $(10-70)$; Comprehensibility $(11-77)$; Meaningfulness $(8-56)$ \}. The scores are kept continuous i.e., higher scores indicate higher levels of Sense of Coherence i.e., higher Manageability, Comprehensibility and Meaningfulness.

\section{Interpersonal Support Evaluation List (ISEL)}

Interpersonal Support Evaluation List is a 12-item measure of perceptions of social support, which had 40 items (20). This questionnaire has three different subscales designed to measure three dimensions of perceived social support, on a four-point scale ranging from "definitely false" to "definitely true." All items are summed to yield a total score (scores range 0-36). Also the scale describes the appraisal, belonging, and tangible subscales (scores range 0-12) comprised of four items each. All scores are kept continuous. Higher scores indicate higher Appraisal, Belonging and Tangible Support. Cronbach's alphas for the ISEL-12 total score were all above 0.70 in the full sample. Convergent validity analyses suggested that the ISEL-12 scores were positively related to social network integration and life engagement, and inversely related to perceived stress and negative effect.

\section{Transgender Identity Stigma Scale(TGISS)}

Chakrapani, et al.,(21) adapted a 11-item 'exposure to transphobia' scale (22) to the Indian context by adding three more items, and tested this 14-item 'transgender identity stigma' scale 4 point likert scale (TGISS) among Indian male-to-female (MtF) TG people. The Transgender Identity Stigma Scale consisted of self-reported ratings on 14 items. Cronbach's alpha was good (0.74) for the whole sample. In split-half reliability analysis, Cronbach's alpha coefficient for part $1=0.72$ and part $2=$ 0.61.Totalnumber of items is 14 with three dimensions - perceived stigma, enacted stigma and consequences of disclosure of transgender identity. The scoring is kept continuous with higher scores indicating higher levels of stigma in each dimension.

\section{Transgender Identity Scale(TIS)}

Sense of identity was assessed using the Transgender Identity Scale. The TIS is a slightly reworded version of the 27-item inventory developed by Mohr and Fassinger (23) that assesses attitudes and feelings about one's gender identity; for example, I will never be able to accept my gender identity until all of the people in my family have accepted me. Items are answered on a 7-point scale from 1 (strongly disagree) to 7 (agree strongly). The TIS yields a global subscale of negative identity, which takes into consideration, certain aspects of transgender identity like internalized transnegativity, need for privacy, need for acceptance, and difficult process). Higher scores on the Negative Identity Index indicate greater negative beliefs about one's gender identity. Validity evidence for the original version of this scale was provided through predicted associations with phase of LGB identity development, degree of investment in one's LGB social identity, self-esteem, and degree of interaction with heterosexual individuals (23). Cronbach's alpha for the current study was 0.84 .

\section{Procedure}

After selecting the measures, a few arrangements were made for data collection. The questionnaires were prepared and organized. All of the research tools were translated into the local language that is Telugu \& back translated into English to check the appropriateness of the Telugu translation. The communities for data collection were contacted. The researcher visited them on the scheduled dates. Rapport was established and they were made aware that their participation in the study was purely voluntary. They were assured of maintaining confidentiality through-out the study. The participants who met the sampling criteria were screened. The participants who agreed to participate in the study were requested to sign an 'Informed Consent Form'. The instructions for the questionnaires were given first and the participants were requested to respond to the items. There was no fixed time limit 
for any of the questionnaires. After completion of data collection, the responses were scored according to the manuals.

\section{RESULTS}

The present study is an exploratory study. Descriptive statistics such as frequency mean, standard deviation, minimum and maximum were computed and the results for the same have been presented in the first section. Regression analysis was performed using SPSS 20 (Statistical Package for Social Sciences) which is presented in the second section.

Table 1 gives the demographic details of the sample. As far as religion is concerned, $73.3 \%$ of the transgender adults followed Hinduism, 19.2\% followed Islam, $6.7 \%$ were Christians and $0.8 \%$ followed Sikhism. The data obtained for relationship status shows that $71.7 \%$ of the transgender people were single, $11.7 \%$ were married, $5.8 \%$ were in a relationship and $8.3 \%$ were in a live in relationship. Table 1 also shows that $87.5 \%$ of transgender people were not employed whereas $7.5 \%$ were employed part time, $3.3 \%$ were students and $1.7 \%$ was employed full time. It can be clearly seen from the table that $21.7 \%$ never attended school, whereas $36.7 \%$ completed their education up to class $10^{\text {th. }}$ However $17.5 \%$ of the transgender adults had attended school up to class $12^{\text {th }}, 20 \%$ were undergraduates, $3.3 \%$ were post graduates and $0.8 \%$ had completed $\mathrm{PhD}$.

Also, $41.7 \%$ of the transgender adults were staying alone, $35 \%$ were staying with friends, $15 \%$ were staying with both the parents, $5 \%$ with one parent and $3.3 \%$ were staying with relatives. Table 1 depicts that $76.6 \%$ of the transgender population had been diagnosed with a physical illness of some kind. As far as mental health was concerned, $94.2 \%$ reported never having visited a psychologist for counselling or therapy, but $5.8 \%$ of the sample reported that they had received counselling. It can be seen from the table that $29.2 \%$ of the sample declined to state their current gender, $28.3 \%$ were transwomen, $20.8 \%$ stated that their current gender was that of a woman, $12.5 \%$ were gender queer, 7.5 were transmen, and $1.6 \%$ stated their current gender to be that of a man. On the other hand $75 \%$ of the sample was declared males at birth, 20\% declined to state their sex at birth and 5\% were females at birth. $37.5 \%$ of the sample reported that an intersex condition was present at birth.

Table 2 shows the levels of sense of coherence and its dimensions - meaning, manageability and comprehensibility were moderate in transgender people. Transegender people also perceived high levels of social stigma from the society and had moderate levels of transgender identity. However, the perceived levels of social support were above average among transgender people.

Table 3 gives the summary results of the regression analysis showing the predictors of sense of coherence and transgender identity among transgender adults. The results depict that perceived social support is a predictor of sense of coherence and two of its three dimensions - manageability and comprehensibility but not meaning and it also predicts transgender identity. Appraisal support one of the dimensions of perceived social support is a predictor of meaning and manageability and not a predictor of comprehensibility and transgender identity. Whereas belonging support and tangible support, the other two dimensions of perceived social support are not predictors of any of the criterion variables - sense of coherence and its dimensions $\&$ transgender identity.

Perceived stigma, a dimension of transgender identity stigma predicts comprehensibility. Enacted stigma, another dimension predicts sense of coherence and its dimension comprehensibility. The third dimension i.e., consequences of disclosure of identity is not a predictor of any of the criterion variables.

\section{DISCUSSION}

Levels of sense of coherence and its dimensions; social support and its dimensions, social stigma and its dimensions and sense of identity were examined in the transgender population.

The moderate levels of sense of coherence in the sample indicates that although the sample is able to make sense of events that occur and they are a part of and they feel that they could cope with it, they may face difficulty in understanding that life in general makes sense and is worth living, this may be 
because they belong to the marginalised section of the society. Similar results were found in the study done by Newfield, Hart, Dibble and Kohler (24) that demonstrates that there was seen a statistically significant diminished Quality of life among female to male transgender participants as compared to US male and female population, particularly in regard to mental health.

Perceived social support and its dimensions - appraisal support, belonging support and tangible support were also assessed in the study. The results show that the levels of social support were high in the sample of transgender people in the present study. Further examination of the dimensions reveals high levels of appraisal support, belonging support and tangible support. This indicated that transgender people had high perceived availability of someone to discuss issues of personal importance, high perceived availability of material aid and high perceived availability of others to interact with socially. Munoz-Plaza, Quinn, and Rounds cite Elia (25) stating that isolation is one of the major contributors to the high-risk status of many LGBT youth. Munoz-Plaza, Quinn and Rounds (25) had results slightly in accordance with the present study. Participants found non-family members, which included peers and non-family adults, to be more supportive than family members. More specifically, participants perceived heterosexual and LGBT-identified friends and non-family adults as providing emotional and instrumental support. However, participants perceived limitations to the emotional support they received from heterosexual peers to whom they disclosed their orientation. In addition to providing emotional support, peers and adults who also identified as LGBT provided valuable informational and appraisal, support. Finally, most participants did not disclose to their parents during high school and perceived their parents and family members as offering limited emotional, appraisal and informational support. Thus research indicates that transgender cause of being marginalised receive less social support, but for the present study the sample of transgender people was selected from a transgender community. There are large communities of transgender people in Hyderabad and Secunderabad who provide support to all the members belonging to that community. The 'guru' and 'chela' system is a source of constant support for the transgender people who are associated with the community for long and those who are newly transitioned and then join the community.

In the present study perceived social stigma and its dimensions - perceived stigma, enacted stigma and consequences of disclosure of transgender identity were also measured. The results showed that there were high levels of perceived social stigma in the sample of transgender people. As far as the dimensions were concerned, results reveal high levels of perceived stigma, enacted stigma and consequences of disclosure of transgender identity. Link and Phelan (26) conceptualized stigma as a collective term that includes recognition and behaviour of societal members that lead to labelling, negative stereotyping, separation, status loss, and discrimination. When internalizing the labelling behaviours of others in the society results in negative consequences, it is defined as perceived stigma (26). Enacted stigma refers to sanctions that are individually or collectively applied to people on the basis of their belonging or perceived belonging to a particular group. Results indicate that high levels of both perceived stigma and enacted stigma was present among the transgender people. Consequences of disclosure of identity was also high in the transgender people, they met with a lot of stigma when they disclosed their true identity. Results of a study done by Doan (27) indicate that although queer spaces provide a measure of protection for gender variant people, the gendered nature of these spaces results in continued high levels of harassment and violence for this population, which is in accordance with current findings.

The term "identity" refers to the capacity for self-reflection and the awareness of self (28). The moderate levels of sense of identity indicate that transgender people face slight difficulty in accepting and understanding their own selves. Similar results were found in the study done by Eliason and Schope (29). Many LGBT people report feeling "different" as children or adolescents. However, the difference can take many forms such as gender atypical interests, not feeling like they fit into any peer group, or not meeting parents' or society's expectations and feeling different often results in alienation and isolation. Many LGBT people report feeling confused at some point and this confusion can be because of incongruence between internal feelings and how one is perceived by others, and/or it can be related to gender-role behaviors, physical appearance, sexual or emotional attractions, 
mannerisms (such as the way one moves one's hands). Confusion can be an unsettling emotional state. Individuals use many methods of identity comparison to others in the mainstream or to those with sexual/gender minority identities.

The two significant predictors of sense of coherence are perceived social stigma and enacted stigma. Perceived social support was positively associated with sense of coherence in transgender people, which has also been found in other studies as well. Skärsäter, Langius, Ågren, Häggströmand Dencker (30) showed that social support is an important cornerstone in the restoration of a person's sense of coherence. Wolff and Ratner (31) found that stress and traumatic events were found to be inversely related to SOC, and social support was positively related, which is in line with the present findings of the study. Langeland and Wahl (32) observed that while social support predicted change in sense of coherence, mental symptoms did not. The results indicate that improving social support might provide important opportunities for increasing sense of coherence among people with mental health problems. Though these studies are done on other population, but the fact that sense of coherence is related to perceived social support applies to the current sample as well. A few people belonging to the present sample reported that over the years based on their experiences and interactions with others, they expect and are prepared to face and deal with the stigma and discrimination based on revealing their identity hence enacted stigma is also related to and a predictor of sense of coherence. However the contribution in the prediction by perceived social support is greater than enacted stigma.

Appraisal support is a significant predictor of meaning. Meaning is a dimension of sense of coherence that refers to how much one feels that life makes sense, and the challenges one faces are worthy of commitment. Appraisal support refers to the perceived availability of someone to discuss issues of personal importance. Dunn and O' Brien (33) showed that social support from a significant other explained variance in meaning in one's life which is line with present findings of the study. Krause (34) indicated that emotional support helps older people cope more effectively with stress by restoring their sense of meaning in life. Wethington and Kessler (35) show that perceived support is, in general, more important than received support in predicting adjustment to stressful life events and challenges which supports the current findings.

The two significant predictors of manageability are appraisal support and perceived social support. The relationship between appraisal support and manageability was negative. On the other hand overall social support had a positive relationship with manageability. However the contribution in the prediction by perceived social support is greater than appraisal support. Manageability is the extent to which a person feels they can cope with whatever happens in life. Hart, Hittner and Paras (36) in a study sought to extend previous research by examining whether individuals scoring high on sense of coherence would perceive social support to be more readily available than individuals scoring low on sense of coherence. Results showed sense of coherence scores were unrelated to the perceived availability of the different types of social support.

Perceived social support, perceived stigma and enacted stigma are predictors of Comprehensibility. Although the relationship between perceived stigma and comprehensibility was negative, the relationship between enacted stigma and comprehensibility was positive. Comprehensibility is the extent to which events are perceived as making logical sense, that they are ordered, consistent, and structured. When compared to enacted stigma, perceived stigma has more ambiguity as it is the person's perception of the stigma and discrimination they may or may not face whereas enacted stigma refers to the stigma that has been acted out upon them. Thus, enacted stigma negatively affects the extent to which one perceives events to be consistent and logical. V.V.M., is a 36 year old transwoman, and has been open and out for the past 15 years as a queer person. She came out very visibly as a transgender activist since 2012 and has worked with the consulting firm Accenture as a Learning \& Development Specialist and had held similar roles earlier with Tatasky. She happens to be one of the founding members of the Telangana Hijra Transgender Samiti, which is an unfunded collective of tansgenders, with hijras, non - hijra intersex people and transwomen, transmen and genderqueers. Being a part of this community for so long she stated that, "there is a lot of stigma 
internalised in the minds of people, they express this in numerous ways, the way they talk to us, the way they treat us and at times it gets way too much to even handle or deal with it."

Perceived social support is a predictor of Sense of identity. Sense of identity can refer to the gender identity which is has been described as an individual's internal sense of self as being, male, female, or an identity between or outside these two categories (37). According to Bornstein and Ben-Yossef (38), gender identity is what we feel our gender should be, male or female, at any given moment. Once a part of the closely knit system of the 'guru' and 'chela', followed in the transgender community, as mentioned by the people, they could in a better way understand and accept their identities and be more open about it at the same time.

One of the limitations of the study is that the demographic details are limited to a particular community. The transgender adults belonging to that community, which was primarily engaged in sex work and beggary and is one of the many sub sets of the entire transgender community, was dominant part of the sample. Hence the results are valid for the same and further research needs to be carried out with a more varied and inclusive group of transgender population and the current study is the first step in this direction.

The present study helps to see the current scenario in the transgender community in an elaborate manner. As it is an exploratory study, a rich data about the demographic details along with the dimensions, sense of coherence, sense of identity, perceived social support and perceived social stigma is presented vividly. The application value of the study is high when it comes to formulating policies, taking into consideration the plight of the transgender community. Policies can be aimed towards organising formal support systems which will help the transgender community gain wider access to resources such as better health, education, housing, employment facilities and opportunities. All this will help in the overall improvement in living conditions of the transgender community thereby ensuring wider acceptance by the society. Also in case the laws have to be reinforced, being transgender friendly is one aspect that needs to be taken into consideration after looking into this study, specifically their employment status. Lastly, acceptance and reintegration of the transgender people in the society is a facet that this study could serve to be useful for. Further research in India among the transgender community can also make use of the existing authentic data.

\section{REFERENCES}

1. Ryland, E., \& Greenfield, S. (1991). Work stress and well being: An investigation of Antonovsky's sense of coherence model. Journal of Social Behavior and Personality, 6(7), 39.

2. Bolger, N., \& Zuckerman, A. (1995). A framework for studying personality in the stress process. Journal of personality and social psychology, 69(5), 890.

3. Naudé, J. L., \& Rothmann, S. (2006). Work-related well-being of emergency workers in Gauteng. South African Journal of Psychology, 36(1), 63-81.

4. Lyons, T., Shannon, K., Pierre, L., Small, W., Krüsi, A., \& Kerr, T. (2015). A qualitative study of transgender individuals' experiences in residential addiction treatment settings: stigma and inclusivity. Substance abuse treatment, prevention, and policy, 10(1), 1.

5. Weinreich, P., \& Saunderson, W. (2003). Analysing identity.

6. Nagoshi, C. (2015). The Intersection of Gender and Sexual Identity Development in a Sample of Transgender Individuals. In Society for Social Work and Research 19th Annual Conference: The social and behavioral importance of increased longevity. Sswr.

7. Testa, R. J., Jimenez, C. L., \& Rankin, S. (2014). Risk and resilience during transgender identity development: The effects of awareness and engagement with other transgender people on affect. Journal of gay \& lesbian mental health, 18(1), 31-46.

8. Amodeo, A. L., Vitelli, R., Scandurra, C., Picariello, S., \& Valerio, P. (2015). Adult Attachment and Transgender Identity in the Italian Context: Clinical Implications and Suggestions for Further Research. International Journal of Transgenderism, 16(1), 49-61. 
9. Quinn, S. C., Rounds, K. A., \& Munoz-Plaza, C. (2002). Lesbian, gay, bisexual and transgender students: Perceived social support in the high school environment. The High School Journal, 85(4), 52-63.

10. Budge, S. L., Adelson, J. L., \& Howard, K. A. (2013). Anxiety and depression in transgender individuals: The roles of transition status, loss, social support, and coping. Journal of consulting and clinical psychology,81(3), 545.

11. Sheets Jr, R. L., \& Mohr, J. J. (2009). Perceived social support from friends and family and psychosocial functioning in bisexual young adult college students. Journal of Counseling Psychology, 56(1), 152.

12. Wright, E. R., \& Perry, B. L. (2006). Sexual identity distress, social support, and the health of gay, lesbian, and bisexual youth. Journal of homosexuality, 51(1), 81-110.

13. Van Brakel, W. H., Anderson, A. M., Mutatkar, R. K., Bakirtzief, Z., Nicholls, P. G., Raju, M. S., \& Das-Pattanayak, R. K. (2006). The Participation Scale: measuring a key concept in public health. Disability and rehabilitation, 28(4), 193-203.

14. Schofield, K. (2015). Protective Factors for Transgender Adults.

15. Lewis, R. J., Derlega, V. J., Griffin, J. L., \& Krowinski, A. C. (2003). Stressors for gay men and lesbians: Life stress, gay-related stress, stigma consciousness, and depressive symptoms. Journal of Social and Clinical Psychology, 22(6), 716-729.

16. Poteat, T., German, D., \& Kerrigan, D. (2013). Managing uncertainty: a grounded theory of stigma in transgender health care encounters. Social science \& medicine, 84, 22-29.

17. Clements-Nolle, K., Marx, R., \& Katz, M. (2006). Attempted suicide among transgender persons: The influence of gender-based discrimination and victimization. Journal of homosexuality, 51(3), 53-69.

18. Srivastava, S., \& Singh, P. (2015). Psychosocial Roots of Stigma of Homosexuality and Its Impact on the Lives of Sexual Minorities in India.Open Journal of Social Sciences, 3(08), 128.

19. Antonovsky, H., \& Sagy, S. (1986). The development of a sense of coherence and its impact on responses to stress situations. Journal of Social Psychology, 126(2), 213-226.

20. Cohen, S., \& Hoberman, H. M. (1983). Positive events and social supports as buffers of life change stress. Journal of applied social psychology, 13(2), 99-125.

21. Chakrapani, V., Vijin, P. P., Logie, C. H., Newman, P. A., Shunmugam, M., Sivasubramanian, M., \& Samuel, M. (2017). Assessment of a "Transgender Identity Stigma" scale among trans women in India: Findings from exploratory and confirmatory factor analyses. International Journal of Transgenderism, 1-11.

22. Sugano, E., Nemoto, T., \& Operario, D. (2006). The impact of exposure to transphobia on HIV risk behavior in a sample of transgendered women of color in San Francisco. AIDS Behav, 10(2), 217-225.

23. Mohr, J., \& Fassinger, R. (2000). Measuring dimensions of lesbian and gay male experience. Measurement and Evaluation in Counseling and Development, 33(2), 66-66.

24. Newfield, E., Hart, S., Dibble, S., \& Kohler, L. (2006). Female-to-male transgender quality of life. Quality of Life Research, 15(9), 1447-1457.

25. Munoz-Plaza, C., Quinn, S. C., \& Rounds, K. A. (2002). Lesbian, gay, bisexual and transgender students: Perceived social support in the high school environment. The High School Journal, 85(4), 52-63.

26. Link, B. G., \& Phelan, J. C. (2001). Conceptualizing stigma. Annual review of Sociology, 27(1), 363-385.

27. Doan, P. L. (2007). Queers in the American city: Transgendered perceptions of urban space. Gender, Place and Culture, 14(1), 57-74.

28. Leary, M. R., \& Tangney, J. P. (2003). The self as an organizing construct in the behavioral and social sciences. Handbook of self and identity, 3-14.

29. Eliason, M. J., \& Schope, R. (2007). Shifting sands or solid foundation? Lesbian, gay, bisexual, and transgender identity formation. In The health of sexual minorities (pp. 3-26). Springer US. 
30. Skärsäter, I., Langius, A., Ågren, H., Häggström, L., \& Dencker, K. (2005). Sense of coherence and social support in relation to recovery in first- episode patients with major depression: A one- year prospective study. International Journal of Mental Health Nursing, 14(4), 258-264.

31. Wolff, A. C., \& Ratner, P. A. (1999). Stress, social support, and sense of coherence. Western Journal of Nursing Research, 21(2), 182-197.

32. Langeland, E., \& Wahl, A. K. (2009). The impact of social support on mental health service users' sense of coherence: A longitudinal panel survey. International journal of nursing studies, 46(6), 830-837.

33. Dunn, M. G., \& O'Brien, K. M. (2009). Psychological health and meaning in life: Stress, social support, and religious coping in Latina/Latino immigrants. Hispanic Journal of Behavioral Sciences, 31(2), 204-227.

34. Krause, N. (2004). Lifetime trauma, emotional support, and life satisfaction among older adults. The Gerontologist, 44(5), 615-623.

35. Wethington, E., \& Kessler, R. C. (1986). Perceived support, received support, and adjustment to stressful life events. Journal of Health and Social behavior, 78-89.

36. Hart, K. E., Hittner, J. B., \& Paras, K. C. (1991). Sense of coherence, trait anxiety, and the perceived availability of social support. Journal of Research in Personality, 25(2), 137-145.

37. Wilchins, R. A. ,2002. "Queerer Bodies.” In J. Nestle, C. Howell, and R. A. Wilchins (eds.), Genderqueer: Voices from Beyond the Sexual Binary. Los Angeles: Alyson.

38. Bornstein, G., \& Ben-Yossef, M. (1994). Cooperation in intergroup and single-group social dilemmas. Journal of Experimental Social Psychology, 30(1), 52-67. 
Table1: Descriptives showing Frequency and Percentage for demographics such as Religion, Relationship Status, Employment status, Educational level, Residential Arrangements, Living Arrangements, Physical Illness, Mental health, Current Gender, Sex at birth and Intersex condition for Transgender adults $(\mathrm{N}=120)$

\begin{tabular}{|c|c|c|c|}
\hline & Demographics & Frequency & Percentage \\
\hline \multirow[t]{4}{*}{ Religion } & Hindu & 88 & 73.3 \\
\hline & Muslim & 23 & 19.2 \\
\hline & Christian & 8 & 6.7 \\
\hline & Sikh & 1 & .8 \\
\hline \multirow[t]{3}{*}{ Residential Area } & Rural & 13 & 10.8 \\
\hline & Semi Urban & 2 & 1.7 \\
\hline & Urban & 105 & 87.5 \\
\hline \multirow[t]{6}{*}{ Educational Level } & Never Attended School & 26 & 21.7 \\
\hline & $10^{\text {th }}$ Class & 44 & 36.7 \\
\hline & $12^{\text {th }}$ Class & 21 & 17.5 \\
\hline & Under Graduate & 24 & 20.0 \\
\hline & Post Graduate & 4 & 3.3 \\
\hline & $\mathrm{PhD}$ & 1 & 0.2 \\
\hline \multirow[t]{4}{*}{ Employment Status } & Employed full time & 2 & 1.7 \\
\hline & Employed part time & 9 & 7.5 \\
\hline & Not Employed & 105 & 87.5 \\
\hline & Student & 4 & 3.3 \\
\hline \multirow[t]{5}{*}{ Relationship Status } & Single & 86 & 71.7 \\
\hline & In a Relationship/ Dating & 7 & 5.8 \\
\hline & In a Living Relationship & 10 & 8.3 \\
\hline & Married & 14 & 11.7 \\
\hline & Divorced & 3 & 2.5 \\
\hline \multirow[t]{5}{*}{ Living Arrangements } & Staying with both parents & 18 & 15.0 \\
\hline & Staying with one parent & 6 & 5.0 \\
\hline & Staying with Relatives & 4 & 3.3 \\
\hline & Staying alone & 50 & 41.7 \\
\hline & Staying with friends & 42 & 35.0 \\
\hline \multirow[t]{2}{*}{ Physical Illness } & Present & 92 & 76.7 \\
\hline & Absent & 28 & 23.3 \\
\hline \multirow[t]{2}{*}{ Mental Health } & Attended Therapy - Yes & 7 & 5.8 \\
\hline & Attended Therapy - No & 113 & 94.2 \\
\hline \multirow[t]{6}{*}{ Current Gender } & Man & 2 & 1.6 \\
\hline & Woman & 25 & 20.8 \\
\hline & Trans man & 9 & 7.5 \\
\hline & Trans woman & 34 & 28.3 \\
\hline & Gender queer & 15 & 12.5 \\
\hline & Decline to state & 35 & 29.2 \\
\hline \multirow{3}{*}{ Sex At Birth } & Male & 90 & 75.0 \\
\hline & Female & 6 & 5.0 \\
\hline & Decline to State & 24 & 20.0 \\
\hline \multirow{2}{*}{ Intersex Condition } & Present & 45 & 37.5 \\
\hline & Absent & 75 & 62.5 \\
\hline
\end{tabular}


Table 2 Descriptives showing Minimum, Maximum, Mean \& SD of Sense of Coherence \& its dimensions; Perceived social support \& its dimensions; Transgender Identity stigma \& its dimensions $\&$ Transgender identity among Transgender adults $(\mathrm{N}=120)$.

\begin{tabular}{lcccc}
\hline & Minimum & Maximum & Mean & SD \\
\hline Sense of Coherence & 62.00 & 158.00 & 113.80 & 19.72 \\
$\bullet \quad$ Meaning & 16.00 & 48.00 & 31.60 & 5.30 \\
• Manageability & 25.00 & 55.00 & 40.18 & 5.19 \\
• Comprehensibility & 17.00 & 64.00 & 41.22 & 7.46 \\
Perceived social support & 16.00 & 48.00 & 34.08 & 7.37 \\
- Appraisal Support & 4.00 & 16.00 & 9.47 & 2.82 \\
- Belonging Support & 4.00 & 16.00 & 9.84 & 2.23 \\
- Tangible Support & 4.00 & 16.00 & 9.62 & 2.14 \\
Transgender Identity stigma & & & & \\
• Perceived Stigma & & & & \\
- Enacted Stigma & 10.00 & 28.00 & 20.62 & 4.89 \\
- Consequences Of Disclosure of TG & 5.00 & 20.00 & 13.19 & 4.47 \\
$\quad$ identity & 2.00 & 11.00 & 5.43 & 1.79 \\
Transgender Identity & & & & \\
\hline
\end{tabular}


Table 3 shows the summary of the step wise regression showing the predictors for Sense of Coherence and its dimensions - Meaning, Manageability and Comprehensibility and Transgender Identity.

\begin{tabular}{|c|c|c|c|c|c|c|}
\hline & Predictor variables & $\begin{array}{c}\text { Sense of } \\
\text { Coherence }\end{array}$ & Meaning & $\begin{array}{l}\text { Manageabilit } \\
\mathrm{y}\end{array}$ & $\begin{array}{c}\text { Comprehensibili } \\
\text { ty }\end{array}$ & $\begin{array}{c}\text { Transgender } \\
\text { Identity }\end{array}$ \\
\hline \multirow{8}{*}{$\beta$} & $\begin{array}{l}\text { Perceived social } \\
\text { support }\end{array}$ & $0.297 *$ & N.S & $0.264 *$ & $0.256^{*}$ & $0.474 * *$ \\
\hline & Appraisal Support & N.S & $0.380 *$ & $-0.287 *$ & N.S & N.S \\
\hline & Belonging Support & N.S & N.S & N.S & N.S & N.S \\
\hline & Tangible Support & N.S & N.S & N.S & N.S & N.S \\
\hline & Perceived Stigma & N.S & N.S & N.S & $-0.346^{*}$ & N.S \\
\hline & Enacted Stigma & $0.220 * *$ & N.S & N.S & $0.239 * *$ & N.S \\
\hline & Consequences of & & & & & \\
\hline & $\begin{array}{l}\text { Disclosure of TG } \\
\text { Identity }\end{array}$ & N.S & N.S & N.S & N.S & N.S \\
\hline \multirow{8}{*}{$\Delta \mathrm{R}^{2}$} & $\begin{array}{l}\text { Perceived social } \\
\text { support }\end{array}$ & 0.061 & N.S & 0.069 & 0.063 & 0.225 \\
\hline & Appraisal Support & N.S & N.S & 0.066 & N.S & N.S \\
\hline & Belonging Support & N.S & N.S & N.S & N.S & N.S \\
\hline & Tangible Support & N.S & N.S & N.S & N.S & N.S \\
\hline & Perceived Stigma & N.S & N.S & N.S & 0.040 & N.S \\
\hline & Enacted Stigma & 0.046 & N.S & N.S & 0.034 & N.S \\
\hline & $\begin{array}{l}\text { Consequences of } \\
\text { Disclosure of TG } \\
\text { Identity }\end{array}$ & N.S & N.S & N.S & N.S & N.S \\
\hline & Total Adjusted R ${ }^{2}$ & 0.092 & 0.137 & 0.120 & 0.114 & 0.218 \\
\hline
\end{tabular}

${ }^{* *} \mathrm{p}<0.01, * \mathrm{p}<0.05, * * * \mathrm{p}<0.001, \Delta \mathrm{R}^{2}$-Change in R squared, $\beta$-Standardized Beta Coefficient, $\mathrm{N}=120$ 